\title{
The Diffusion of Workplace Antidiscrimination Regulations for the LGBTQ+ Community
}

\author{
Helen Seitzer
}

\section{Introduction $^{1}$}

Today's media are flooded with news: Millennials (born 1980-1990) are the "gayest generation" in human history (Allen 2017). In 2020, it was estimated that $4.5 \%$ of the US population identifies as LGBTQ+ (Lesbian, Gay, Bi-, Transsexual, Queer, and other) (The Williams Institute 2020). The public confusion over acronyms and pronouns goes so far that people ironically label the LGBTQ+ community "alphabet mafia" on social media platforms (Alphabet Mafia 2020). Gender-neutral

\footnotetext{
${ }^{1}$ This chapter is a product of the research conducted in the Collaborative Research Center "Global Dynamics of Social Policy" at the University of Bremen. The center is funded by the Deutsche Forschungsgemeinschaft (DFG, German Research Foundation)-project number 374666841-SFB 1342.
}

H. Seitzer $(\varangle)$

SOCIUM, University of Bremen, Bremen, Germany

e-mail: seitzer@uni-bremen.de 
language was implemented by the US government (Aldridge 2021), while at the same time, 54 countries were still criminalizing same-sex relationships in $2019 .{ }^{2}$ Despite the rising global visibility and acceptance of people breaking with binary gender stereotypes, sexual preferences, and the traditional 'nuclear family' constellations, there is still a large gap when it comes to integration of people from the LGBTQ+ community into everyday society. ${ }^{3}$ The community is not only facing difficulties in their private lives, but also unfair treatment and discrimination in the workplace. In 2017, over 20\% of Americans who identify as part of the LGBTQ+ community, reported to have been discriminated against in the workplace during the job application process. Other common issues include missing out on promotions, not receiving equal pay, verbal abuse, and mistreatment through the courts. These discriminatory practices nearly double if multiple disadvantages intersect, such as ethnicity or socioeconomic background (Casey et al. 2019). To ensure that all people, regardless of their sexual preferences, can participate equally and discrimination-free in the labor market, some states have resorted to including the LGBTQ+ community in workplace antidiscrimination policies. However, this movement is a newer topic on states' agendas and is progressing rather slowly, in addition, it is rarely discussed on the international stage. While some states such as France, have introduced antidiscrimination policies on the basis of gender already in 1985, others are still hesitant. This chapter asks if transnational networks are contributing to the diffusion of antidiscrimination policies for the LGBTQ+ community by adding transnational pressure to inspire policy adoption, or if this policy type is more dependent on local conditions.

For supporters of the LGBTQ+ community the need for political action is undisputable. Adversaries, however, question, why the state should get involved in such a private matter. This question leads to the discussion of a welfare states' responsibilities. According to the Universal

\footnotetext{
${ }^{2}$ Own coding.

${ }^{3}$ In this chapter, the term "community" refers to people of the LGBTQ+ community, not only non-conforming regarding their own gender identity but also regarding their sexual orientation. Due to lack of data, the included legal regulations do not include relationships breaking with the status of a nuclear (2-parent) family or include multiple consenting adults (polyamory). In addition, these regulations do not specifically mention transgender or transsexual people, but the theoretical framing does include this group as well.
} 
Declaration of Human Rights (UDHR) (UN General Assembly 1948), the state has the responsibility to ensure, among other things, every persons' security, safety, and freedom, regardless of origin, race, sex or religion. This includes, as many activists of the gay rights movement claim (Velasco 2018), the freedom to choose one's partner regardless of gender. The International Covenant on Economic, Social and Cultural Rights (ICESCR) (UN General Assembly 1966), signed by 171 countries, goes even further by declaring, that a state's responsibility includes ensuring the right to be recognized "without discrimination of any kind as to race, color, sex, language, religion, political or other opinion, national or social origin, property, birth or other status" (Article 2.2). Given the global acceptance of these sets of definitions and responsibilities, regulations ensuring the safety, well-being, and non-discrimination of the LGBTQ+ community should therefore be seen as a constitutive part of states' welfare responsibilities, along with ensuring equal opportunities and economic security. Ensuring a safe, discrimination-free workplace is important for the livelihood of individuals and the community. Multiple institutions such as the International Labor Organization (ILO) are concerned with fostering the implementation of such policies across the globe.

However, the reality of rights and protections for the LGBTQ+ community looks very different. While the acceptance of LGBTQ+ persons is slowly rising, the implementation of equal rights for couples of the same gender as well as other family constellations aside from the nuclear 2-parent-1-child household is still very low. The implementation of protection laws is equally low in prevalence and similarly new, just as marriage or civil union laws, as Fig. 9.1 shows. This chapter therefore explores how global and local conditions such as countries' interdependencies and national cultural values influence the diffusion of workplace antidiscrimination regulations for the LGBTQ+ community.

\section{Setting up a Timeline}

To put the adoption of antidiscrimination regulations as analyzed in this chapter into perspective, it is helpful to set up a timeline of how 


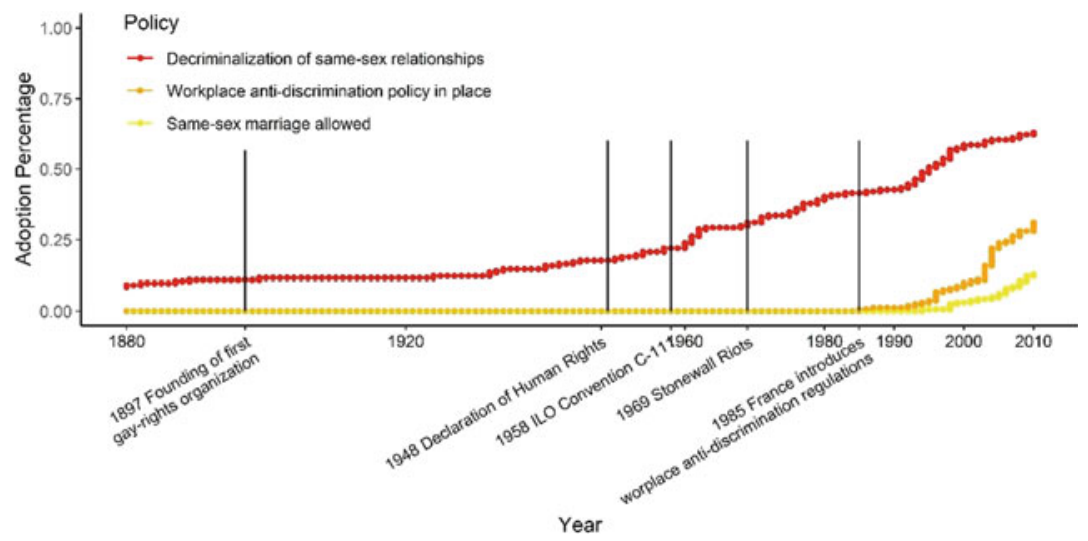

Fig. 9.1 Cumulative adoption rates for LGBTQ+ rights and important dates

LGBTQ+ issues progressed internationally over the years from local gay rights organizations to internationally celebrated pride. This exploration already contains clues about the results of this chapters' analyzes. This timeline not only includes important events leading up to the implementation of antidiscrimination policies, but also discusses the progression from criminalizing same-sex relationships to their acceptance in society as a prerequisite to the implementation of antidiscrimination regulations for the community. Even though most societies today are open towards the LGBTQ+ community, discrimination against the community is still an issue, as discussed previously.

Throughout early human history, having relations with the same sex or not conforming to popular gender norms was very common (LGBT History 2021). But, with the rise of Christianity these relations began to lose acceptance and were deemed "deviant" and criminal behavior. Especially with the rise of modern sciences, medical procedures, and psychology, this oppression strengthened (Edsall 2003). The struggle for the community to be allowed to openly express their personality and sexuality in public developed different forms around the globe. The Scientific Humanitarian Committee was a Berlin-based organization, founded as early as 1897, which is generally accepted as the first gay rights organization. Figure 9.1 shows that at this point in time, same-sex relationships were decriminalized in some countries, but it took 
considerably longer to include regulations for protection or even the implementation of equal rights in marriage. Of course, this organization was shut down during the Nazi rule in 1933 and its members suffered greatly under the Nazi regime (Encarnación 2014). These topics then resurfaced in Europe again already in 1948 with the signing of the UDHR. This document, especially Article 2, granting the "rights of freedom ... without distinction of any kind, including sex", has since then been used by activist groups to frame their arguments, declaring the choice of partners and personal expression a human right (Encarnación 2014). Interestingly, a study by Velasco (2018) showed, that increased activism for equality and human rights often coincides with increased activism for LGBTQ+ rights as well. The combining of forces for these causes can be controversial but, in some cases, also be beneficial for both parties (Velasco 2018). While the acceptance of same-sex partnerships is a prerequisite for the implementation of any policy to protect LGBTQ+ community members from discrimination, it is also important to note when antidiscrimination laws for the general population, regardless of sexual preference, became important on the international stage.

Therefore, another historical event to consider in this chapter is the ratification of the ILO Discrimination (Employment and Occupation) Convention C111 (1958). This convention, which is ratified by 175 countries worldwide, states in the Preamble, that.

... all human beings, irrespective of race, creed or sex, have the right to pursue both their material well-being and their spiritual development in conditions of freedom and dignity, of economic security and equal opportunity, and Considering further that discrimination constitutes a violation of rights enunciated by the Universal Declaration of Human Rights...

Article (1a) states that "any distinction, exclusion or preference made on the basis of race, colour, sex, religion, political opinion, national extraction or social origin" is to be considered as discrimination. Unfortunately, as statistics show, discrimination, in the workplace or elsewhere, on basis of sexual orientation is still a common occurrence in many states. Even though there were many public transgressions to the general norm throughout history and a secret subculture existed in America and 
Europe, it took until 1969 for the LGBTQ+ community in the US to open the fight for their rights to a public, discrimination-free life as well (Edsall 2003). The Stonewall riots, a violent clash between police and patrons of Stonewall Inn, a transvestite and gay bar in Manhattan, is now considered the beginning of the open fight for LGBTQ+ rights, as this clash was followed by the first gay pride parade in the world. The open fight for equal rights eventually led to the realization, that antidiscrimination regulations protecting the LGBTQ+ community, not only in the workplace, are a necessity to ensure the equal participation of this group in the labor market and everyday life. Today, the fight for equal rights of the community often lies in the hands of local and international organizations (IOs) and non-governmental organizations (NGOs) like the International Lesbian, Gay, Bisexual, Trans and Intersex Association (ILGA), which is considered the largest transnational IO advocating for LGBTQ+ rights today. Figure 9.1 shows the adoption rates for the decriminalization of same-sex relationships, the adoption of antidiscrimination laws in the workplace, and the adoption rates for marriage or civil union laws for same-sex couples. This timeline clearly demonstrates how the acceptance of private relationships long preceded the acceptance and support of antidiscrimination regulations and family units potentially involving children. It also establishes that in the past, local events seem to have been more prevalent in inspiring societal change, rather than international pressure influencing policies. Nevertheless, the effect of transnational influence cannot be dismissed.

Due to the combination of these events, the political definition of human rights in the UDHR, which was then followed by other public events and a global, political debate, the year 1948 will serve as a starting point for this analysis.

Until 2010, 104 countries of the 164-country sample used in this chapter had actively removed laws previously criminalizing relationships among people of the same gender, effectively making same-sex relationships legal. The societal acceptance thereof is a different story, but this discussion would exceed the scope of this chapter. Only 5 countries in the sample did not have any criminalization or decriminalization laws in place, however, several countries such as Iraq did not have a specific criminalization law in place but are known to find other ways of enforcing 
norm digressions, or had laws limiting the freedom of expression of persons (Egypt) (Mendos et al. 2020). Others simply had never criminalized LGBTQ+ relationships, or there was no clear data found. In 2020, 54 Countries still had active laws criminalizing LGBTQ+ relationships or limiting their freedom of expression. 66 countries had implemented regulations preventing discrimination at the workplace on basis of sexual orientation.

The acceptance of relationships contrary to the common norm differs significantly from the inclusion of the community in all aspects of public life. The legalization or decriminalization of same-sex relationships started much earlier than the adoption of laws giving the community the same rights as everyone else, as Fig. 9.1 shows (Encarnación 2014). In addition, there are considerable differences in local and national regulations. For example, Wisconsin was the first US state to ban discrimination based on sexual orientation in both public and private sector employment in 1982, but the regulation was only implemented in 2020 on the national level (Johnson 2016). France, on the other hand, banned discrimination based on sexual orientation already in 1985 for the entire country. While antidiscrimination regulations are making strong progress, equal marriage rights are only slowly being introduced. Adoption rights are lagging still further behind. This shows that participation in the workplace might be considered a more important aspect to ensure than those allowing the socialization of children by same-sex couples, as this goes along with the impression of fostering non-traditional families and decay in Christian morals.

This global divergence in adoption of rights for the LGBTQ+ community begs the question of why some countries try to ensure a discrimination-free workplace and "fulfillment of citizen duties" (e.g., contributing to the economy) regardless of sexual orientation while others do not. Previous research has found various reasons, local conditions such as activism, urbanization, religiosity but also international problem pressure (e.g., Ayoub and Page 2020; Ayoub 2015; Colvin 2004). This problem pressure can be administered through IOs and other advocacy groups, but also other policymakers, which then ultimately leads to policy diffusion. While policy diffusion, local culture, 
and religion have been a part of previous research on the topic, the inclusion of additional networks such as trade, has not been considered yet. This chapter therefore intends to fill this gap.

When looking at the statistics but also the declarations and regulations presented above, one immediately wonders what other global or local factors might drive the introduction of rights and policies for the LGBTQ+ community, and what players or factors are preventing it. This chapter therefore sets out to explore different networks of policy diffusion. Do transnational trade networks, spatial proximity, colonial ties and cultural similarities have an impact on the diffusion of workplace antidiscrimination regulations for the LGBTQ+ community? Or do domestic factors have a stronger impact on the implementation of these policies, indicating no norm diffusion regarding this policy? The policies include all regulations prohibiting discrimination in the workplace due to sexual preference and expression.

In the following section, I will clarify my theoretical approach and contextualize the chapter with previous research. I will then discuss the methodology and data used and then discuss the results, conclusion, and limitations of this analysis.

\section{Theory}

Policy diffusion has multiple explanatory mechanisms through which policies travel from one country to another, namely learning, competition, imitation, or coercion (Dobbin et al. 2007). All the mechanisms share the commonality that policies are traveling from one country to another through a connection between them. This could be a colonial relationship, resulting in a coercive diffusion; a trade network resulting in competition; or simply communication through either unneighborly relations or general interactions between policymakers and advocates, or IO membership, fostering policy learning. The mechanism at work here is "contagion": if a country has adopted a norm, all countries tied to this country are exposed to this fact and their risk of adoption increases if the policy is contagious. The more countries are embedded into different 
networks, the more likely they are to adopt policies similar to network partners' (Boli and Thomas 1999).

A common theoretical approach to this is Meyer and colleagues' world society theory (Meyer et al. 1997). According to this theoretical approach, countries and policymakers draw from a common set of accepted norms and ideas about social policies and rights, such as the construct of democracy or human rights, for policy inspiration. Through networks of interaction, such as trade, simple spatial proximity, shared IO membership, or colonialism, the members of world society exchange information which ultimately allows for policy diffusion. The members of world society also hold each other accountable for adhering to these commonly accepted standards. Consequently, the adoption of these standards can allow countries to legitimize themselves and "put themselves on the map." To conclude, countries care about their image and reputation on the world stage and new adopters are implementing policies when under pressure to do so. In addition, if these norms are not adopted, punitive action can occur. Thus, through this framework, the international community is said to enforce the diffusion of these standards to the point where this development seems inevitable. The increase in exposure through different networks and IOs results in a deeper embedding in world society and increases the risk of adoption (Velasco 2020b; Boli and Thomas 1999).

While the networks of world society lead to the diffusion of norms, which norms are diffusing can be explained by neoinstitutionalist theory. According to this theoretical strand, international organizations as rationalized others develop and implement norms and values in world society, resulting in an increasing isomorphism of different institutions around the globe. Most of these norms are based on rational arguments based on increasing efficiency. Antidiscrimination policies increase the participation and therefore also productivity of the LGBTQ+ community, effectively improving citizens' labor market participation and a countries' economic productivity (Dobbin et al. 2007). Therefore, especially countries based on neoliberal values could be expected to implement antidiscrimination policies for the LGBTQ+ community so as not to prevent a large portion of society from contributing to economic productivity. 
However, this is not always the case. In fact, with issues such as LGBTQ+ rights the increased pressure through world society might even invoke an adverse reaction (Rahman 2014). Studies have found that while there is a positive change in attitudes toward homosexuality in general due to the work of IOs and world society, the gap between liberal, more religious societies has widened (Roberts 2019; Ayoub and Page 2020; Ayoub 2015). In fact, the framing of LGBTQ+ rights as "foreign values" from the West is not uncommon. Ironically, some African countries criminalizing LGBTQ+ relationships do so in direct reference to their British colonial heritage - a Western influence (Encarnación 2014). Interestingly, shaming through world society due to non-compliance might even support the resistance to these norms, if the local societal situation does not agree with the international normas it is often the case in religious communities or countries. In fact, if countries do not have an internal motivation to implement these norms, resistance to shaming might even legitimize legislators in the eyes of their local population (Terman 2019). Nevertheless, it seems as if world society has some effect on the introduction of LGBTQ+ policies, as does culture, just maybe not exclusively in a positive direction. Therefore, I consider different networks of possible policy diffusion, as mentioned before, along with several local conditions as control variables to test if workplace antidiscrimination laws diffuse through the "usual" channels or if there are other mechanisms at play.

\section{Previous Research}

There is a surprisingly large body of literature on LGBTQ+ policies available-considering the novelty of the issue. But many of these studies focus on the implementation of different regulations or bans in individual countries, or societal acceptance or rejection of LGBTQ+ issues, instead of policy development and diffusion. Interestingly, a large body of these studies is focused on the United States; fewer studies provide a global perspective. Nevertheless, there are several studies relevant to this chapter. Many studies identify local cultural characteristics as defining factors. 
Johnson (2016) found that the lack of national pressure, combined with an active LGBTQ+ community, results in a federal instead of national implementation of policies for the community. In addition, the presence of an active group advocating for gender and racial equality positively contributes to the introduction of LGBTQ+ policies. In a similar perspective, more women in parliament tends to increase the number of social welfare policies and therefore positively influence the introduction of LGBTQ+ policies as well (Velasco 2018). Based on these results, a gender equality index was integrated into the analysis of this chapter to control for the local culture and perspective on women.

Another study on the implementation of LGBTQ+ rights, especially in the workplace, states as well that internal activism, even though not necessarily visible to the outside world, is the driving force behind antidiscrimination regulations in Fortune 1000 companies. However, the author also states that without the cultural capacity to allow such a "transgression" against traditional norms, activism would not be possible in the first place (Raeburn 2004).

Although a lot of evidence points to the influence of local culture and conditions on the introduction of these policies, it has to be mentioned that the internal pressure to implement these policies is often higher in industrialized, urban regions due to the higher chances of a more diverse community (Colvin 2004).

According to Taylor and colleagues (2012) the risk of adoption of LGBTQ+ as well as transgender rights also depends highly on the specific subject of the policy: While regulations providing antidiscrimination protections on the basis of sexual orientation are highly dependent on internal political factors such as the capacity and use of local initiatives, education rate, and a divided government; for gender identity issues, this is not the case. The authors add that even though there are no clear diffusion pathways discernible, the isomorphism they found between countries is suspicious and does hint toward a world society model of policy diffusion. Another indicator supporting the influence of world society has been found by Fernández and Lutter (2013) as well. This study finds that political, secular-rational values as well as socioeconomic factors drive the implementation of these policies, aside from world society ties. World society ties are here defined as membership 
in different IOs and ratified human rights treaties. Interesting in this study is the positive effect of domestic cultural, rational values. These results indicate that not only are local cultural conditions such as female empowerment, activism, and economic factors influencing the implementation of these policies, but also ties through shared IO membership and shared perspectives on human rights.

Despite these studies showing the increase of LGBTQ+ protection regulations, several studies have found that with growing advocacy groups and international visibility, the resistance to implement these norms is also growing. Outside the West, resistance of local LGBTQ+ groups is rising, which becomes visible through disagreements with the international norm, as well as activism groups, especially human rights organizations, not wanting their arguments to be "hijacked" ("gay rights are human rights"). This can put pressure on local lawmakers to prevent the implementation of LGBTQ+ rights (Velasco 2018). Rahman (2014) also points out, that in many countries not classified as "the West," the international pressure to implement legal regulations which were previously implemented in the West can lead to what the author calls a "homocolonialist" perspective. The resistance to these laws has less to do with the subject itself, but rather with the opposition to the West, especially if the invoked Western exceptionalism fosters a confrontational, hierarchical relationship between countries, where not adopting these norms is not only seen as "trailing behind" but even as "inferior." Thus, when the international pressure to implement LGBTQ+ laws does not respect individual societal backgrounds and instead antagonizes society and lawmakers alike, even shaming the country internationally, this pressure can lead to an oppositional action (Terman 2019).

As these studies show, there are many local but also transnational conditions fostering the implementation of LGBTQ+ policies. A new factor in this chapter is the use of exposure to countries with shared cultural characteristics as a transnational network of influence. Are lawmakers only responding to local cultural conditions or are they also reacting to actions of lawmakers in countries with a similar cultural profile? Based on these results, the following aspects are considered in this analysis: aside from a network of cultural similarity, colonial ties, spatial proximity, and trade, several societal conditions were included: 
a gender equality index as well as the ratification of the ILO convention C111 against discrimination, GDP per capita and a democratization index. Furthermore, as a proxy for embeddedness in world culture, the indegree of the trade network is used. Trade openness (Busemeyer 2009) was tested for, but not included.

\section{Data and Methods}

The chapter analyzes predictors influencing the introduction and diffusion of workplace antidiscrimination laws for the LGBTQ+ community from 1949 until 2010 for $N=164$ countries. The data was collected from the ILGA reports on State-Sponsored Homophobia (e.g., Mendos et al. 2020). These regulations include all acts or laws that prohibit discrimination based on sexual orientation, even if this stipulation is one of several mentioned in the act. For example, New Zealand included sexual orientation for the first time in 1993: Section 21(1)(m) of the Human Rights Act names sexual orientation among the prohibited grounds of discrimination. Article 22 of this act prohibits discrimination in employment, thereby covering discrimination in employment based on sexual orientation. This regulation was then revised and in 2000, Article 105(1)(m) of the Employment Relations Act specifically prohibits employment discrimination based on sexual orientation. In many cases, acts were vague at first, only covering sexual orientation and gender identity was added later on. France for example, named sexual orientation in 1985 as grounds protected against discrimination under the Labour Code and in 2008, gender identity was included. All first mentions of protection against discrimination or equal treatment in occupation, workplace, trade, or profession with regards to sexual preference or orientation were included. If sexual orientation was included as an amendment, the date of amendment was set as the introduction. Introductions were only coded if the regulation was introduced for the entire state. In cases like the United States, for example, some local states introduced antidiscrimination laws much earlier than the federal level: The District of Columbia covered sexual orientation already in 
1973 (D.C. Code $\$ 2-1402.11),{ }^{4}$ but it was only included in federal legislation in 2020. In this case, the federal regulation was coded.

The networks on shared cultural characteristics (or cultural spheres), which are considered of special interest in this chapter, include indicators of political liberties, rule of law, gender roles, dominant religion, language group, government ideology, classification of civilization, and colonial past (Besche-Truthe et al. 2020). In addition, a network of trade (Barbieri and Keshk 2016), colonial relationships (Becker, 2019 enriched with Head and Mayer, 2014; and our own data collection using Wikipedia), and spatial proximity (Eiser et al. 2020) is considered to potentially influence the diffusion process (see Mossig et al. 2021, in this volume, for a detailed description of the data and procedure). Aside from the network exposure, several indicators were included: The degree of trade, describing the number of trade ties a country has in any given year as indicator for a countries' embeddedness into a globalized world. More ties in trade could indicate a deeper embeddedness in world society and therefore a stronger pressure to implement antidiscrimination regulations. This indicator is not to be confused with a trade openness measure (Busemeyer 2009), which was tested but not significant. Additionally, GDP per capita (Inklaar et al. 2018) was controlled for, missing data on this indicator was interpolated with a logistic function to account for the nonlinear rise of GDP. Further, the democracy index from the V-Dem Project (Lührmann et al. 2018) was included. Missing data points were interpolated linearly. These indicators allow testing for the influence of economic situation as well as political regime. Also, a historical gender equality index was included, to account for local awareness of equality and potential activism (Dilli et al. 2019). The missing time points were interpolated linearly as well. Finally, the ratification of the ILO Discrimination (Labour and Occupation) Convention C111 regarding antidiscrimination was controlled to identify if the ratification of a general agreement regarding antidiscrimination irrespective of sexual orientation, had an influence on the adoption of this more specific

\footnotetext{
${ }^{4}$ https://code.dccouncil.us/dc/council/code/sections/2-1402.11.html.
} 
antidiscrimination regulation (data collected by Hahs, Chapter 8 in this volume). This influence has not been tested in other studies before. The diffusion of the ratification of this ILO convention is analyzed in this volume as well, further information can be found in Chapter 8 by Hahs.

For the analysis the R package netdiffuseR (Vega Yon and Valente 2020) was used. Exposure is defined as the share of $j$ adopters in the ego-centered network of node $i(i \neq j)$ at time $t$. Exposure is set to influence the adoption rate between $t$ and $t+1$ (Valente 1995). If all countries, one specific country (ego) is connected to have implemented the policy before ego, exposure is 1 . If none have adopted, exposure is 0 (see Mossig et al. 2021, in this volume, for details of these concepts). The weighted exposure term is then used in a discrete-time logistic-hazard model to predict its influence on the introduction probability of the dependent variable. Once a country has introduced the policy, it leaves the risk set. Introductions after 2010 are right-censored. The standard errors were corrected with a clustering indicator for historically dependent units, such as the former Yugoslavia, which could introduce a policy for multiple modern political entities at once. The logistic hazard model is only estimated for the years 1949 until 2010, as antidiscrimination only came onto the international agenda in 1948 with the signing of the UHDR. As mentioned previously, this is because this convention is often used to argue for the introduction of antidiscrimination regulations and is therefore seen as the starting date for the public and political debate about antidiscrimination laws. The effects are displayed in hazard ratios, coefficients greater than 1 denote a positive effect, coefficients smaller than 1 denote a negative effect.

\section{Results}

Figure 9.2 shows a world map of the diffusion of antidiscrimination policies for the LGBTQ+ community. The figure demonstrates that this policy is a new topic and has made significant changes in the last few years, especially after 2010. Most policy fields included in this volume have an "epicenter" of policy origin, in this case, it is European and other English-speaking countries. 


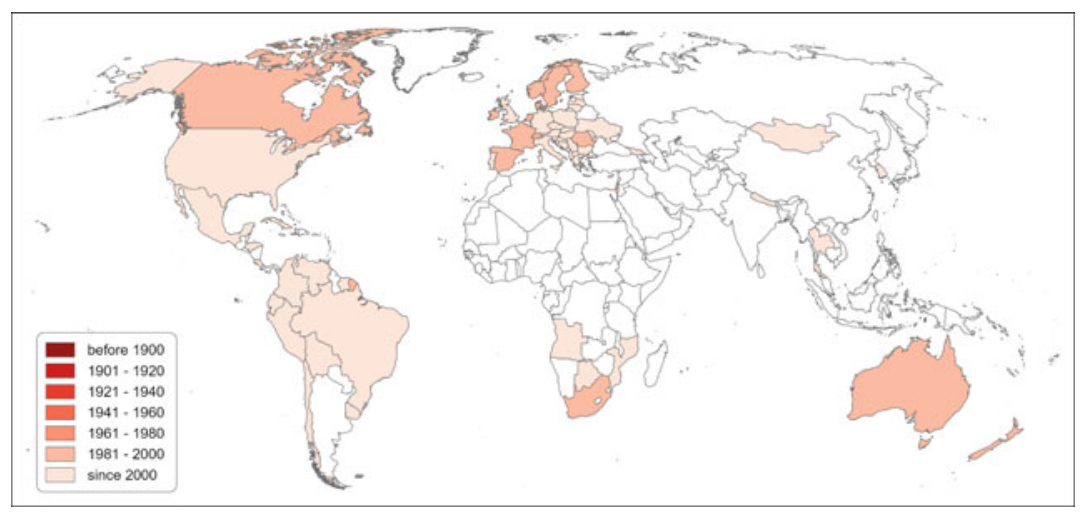

Fig. 9.2 The global diffusion of antidiscrimination regulations in the workplace for the LGBTQ+ community

Table 9.1 shows the hazard ratios of the discrete-time hazard model of introduction of antidiscrimination regulations in the workplace for the LGBTQ+ community. The logistic-hazard model includes $N=126$ countries. ${ }^{5}$ The original dataset in this volume includes political entities which are important for the exposure through the networks but are no longer existent, and not all datasets of the independent variables can provide information on these entities_resulting in a reduced sample.

\footnotetext{
${ }^{5}$ Afghanistan, Albania, Algeria, Argentina, Armenia, Australia, Austria, Bahrain, Bangladesh, Belgium, Benin, Bolivia, Botswana, Brazil, Bulgaria, Burundi, Cambodia, Cameroon, Canada, Central African Republic, Chile, China, Colombia, Congo-Brazzaville, Congo-Kinshasa, Costa Rica, Côte d'Ivoire, Croatia, Cuba, Czechia, Denmark, Dominican Republic, Ecuador, Egypt, El Salvador, Estonia, Eswatini, Finland, France, Gambia, Germany, Ghana, Greece, Guatemala, Haiti, Honduras, Hungary, India, Indonesia, Iran, Iraq, Ireland, Israel, Italy, Jamaica, Japan, Jordan, Kazakhstan, Kenya, Kuwait, Kyrgyzstan, Latvia, Lesotho, Liberia, Libya, Lithuania, Malawi, Malaysia, Mali, Mauritania, Mauritius, Mexico, Moldova, Mongolia, Morocco, Mozambique, Myanmar (Burma), Namibia, Nepal, Netherlands, New Zealand, Nicaragua, Niger, Norway, Pakistan, Panama, Paraguay, Peru, Philippines, Poland, Portugal, Qatar, Romania, Russia, Rwanda, Saudi Arabia, Senegal, Sierra Leone, Singapore, Slovakia, Slovenia, South Africa, South Korea, Spain, Sri Lanka, Sweden, Switzerland, Syria, Tajikistan, Tanzania, Thailand, Togo, Trinidad and Tobago, Tunisia, Turkey, Uganda, Ukraine, United Arab Emirates, United Kingdom, United States, Uruguay, Venezuela, Vietnam, Yemen, Zambia, Zimbabwe.
} 
Table 9.1 The introduction of workplace antidiscrimination regulations, $N=$ 126 countries, $1949-2010$

\begin{tabular}{|c|c|c|c|c|}
\hline & \multicolumn{4}{|c|}{$\begin{array}{l}\text { Introduction of workplace } \\
\text { antidiscrimination regulations }\end{array}$} \\
\hline & (1) & (2) & (3) & (4) \\
\hline > 1995 & $0.000^{* * *}$ & $0.000^{* * *}$ & $0.000^{* * *}$ & $0.000^{* * *}$ \\
\hline 1995-2003 & $0.000^{\star * *}$ & $0.000^{* * *}$ & $0.000^{* * *}$ & $0.000^{* * *}$ \\
\hline 2004-2010 & $0.000^{* * *}$ & $0.00000^{* * *}$ & $0.000^{* * *}$ & $0.000^{* * *}$ \\
\hline $\begin{array}{l}\text { GDP per capita/10000 } \\
\text { USD }\end{array}$ & 1.170 & 1.123 & 1.194 & 1.209 \\
\hline democratization & $1.699^{\star * *}$ & $1.685^{\star * \star}$ & $1.864^{\star * \star}$ & $1.849^{* * *}$ \\
\hline $\begin{array}{l}\text { ratification of ILO } \\
\text { convention C-111 }\end{array}$ & 3.507 & 2.964 & 2.456 & 2.406 \\
\hline gender equality index & $1.139^{* * *}$ & $1.132^{\star * *}$ & $1.143^{* \star *}$ & $1.144^{* * *}$ \\
\hline degree trade network & $1.025^{*}$ & $1.020^{+}$ & $1.028^{*}$ & $1.030^{*}$ \\
\hline $\begin{array}{l}\text { cultural spheres net.: w. } \\
\text { exposure (lag } 1 \text { year) }\end{array}$ & $0.011^{*}$ & $0.011^{*}$ & $0.001^{* *}$ & $0.001^{* *}$ \\
\hline colonies net.: w. exposure & & $0.371^{*}$ & $0.359^{*}$ & $0.321^{*}$ \\
\hline $\begin{array}{l}\text { trade net.: w. exposure } \\
\text { (lag } 1 \text { year) }\end{array}$ & & & 98.960 & 204.648 \\
\hline $\begin{array}{l}\text { spatial proximity net.: w. } \\
\text { exposure (lag } 1 \text { year) }\end{array}$ & & & & 0.339 \\
\hline Observations & 7448 & 7448 & 7448 & 7448 \\
\hline Log Likelihood & -150.315 & -148.107 & -146.619 & -146.545 \\
\hline Akaike Inf. Crit & 318.631 & 316.214 & 315.239 & 317.09 \\
\hline
\end{tabular}

Note $+p<0.1 ;{ }^{*} p<0.05 ;{ }^{* *} p<0.01 ;{ }^{* *} p<0.001$

The time sections were chosen depending on the cumulative adoption function of the policies (see Fig. 9.1).

The model shows that GDP per capita has no significant positive effect on the introduction of workplace antidiscrimination regulations. In contrast, the effect of the democratization index is positive and significant in all models. Interestingly, the signing of the ILO convention C111 regarding antidiscrimination does not have a significant effect on the introduction of antidiscrimination laws for the protection of the LGBTQ+ community. The gender equality index is significant and positive as well, denoting that countries with more women in power, in the workplace, and involved in public life, are more likely to also introduce 
antidiscrimination laws to protect LGBTQ+ people in the labor force This is in line with findings from Velasco (2018) and others, showing that in general, a higher prevalence of women's rights activism and public participation in a country has positive effects on LGBTQ+ rights and representations.

Another interesting result is the degree effect of the trade network, showing the effect of a larger number of trade partners on the risk of adopting policies regardless of exposure to already "infected" countries. Countries with more ties in trade have a higher risk of implementing these regulations. In terms of exposure through the networks, we can see that the exposure effect through the cultural spheres network converges toward 0 -in hazard ratios, this is a large negative effect. The effect is statistically significant. The negative sign is an initially counterintuitive result. Similarly, ties based on colonial relationships have a negative, significant effect on a normalized model. The exposure through these particular networks slows the diffusion process down or even prevents it. The exposure through the trade network is insignificant and positive, but also incredibly large. To test if the trade embeddedness effect could be representative for trade openness (total trade/GDP; Busemeyer 2009), this effect was tested as well, but was not significant. ${ }^{6}$ The pseudoR-square measure by McKelvey and Zavoina (1975) however indicates that the trade embeddedness effect contributes significantly to the model fit, as it improves from 0.74 to 0.83 with the inclusion of the trade degree effect. Spatial proximity has no significant effect. To take different methods of calculating exposure into account, the exposure calculation for the colonial ties network was changed to represent a non-normalized coefficient (the exposure effect reduces over time instead of remaining stable after decolonization). This model can be found in the appendix. Although the colonial ties network loses its significance, the effect directions and sizes of all other coefficients remain relatively stable, supporting the findings.

${ }^{6}$ Model not shown. 
As a result, I therefore conclude that (1) the cultural spheres network does not aid in the diffusion of antidiscrimination laws. While the influence of exposure through the cultural spheres network is significant, the effect is negative. It therefore seems to hinder diffusion instead. However, while cultural similarity seems to halt the diffusion. (2) Being embedded in a trade network has a positive effect, regardless of previous adoptions through other countries. And (3) domestic factors are the main drivers of this policy type. As gender equality and democratization index have such strong positive effects, the influence of local culture is undeniable. However, this instance seems to depend on the local problem pressure and situation and much less on transnational pressure. The international community of world society does not seem to influence the diffusion of this type of policy, rather, it seems to slow the diffusion down. This finding might hint towards a similar mechanism as discussed by Terman (2019), according to whom global pressure and a mismatch to local conditions can hinder the implementation of these policies. The frequent interaction with other countries through trade does have some effect, but it does not justify a diffusion model in the classical sense.

\section{Conclusion \& Discussion}

In this chapter, I have examined the diffusion of antidiscrimination regulations in the workplace for the LGBTQ+ community. I have tested the influence of exposure through networks of cultural similarity, colonial past, trade, and spatial proximity. In addition, I tested the influence of domestic conditions, such as GDP per capita, gender equality, democracy, and the ratification of the ILO's C111 convention for antidiscrimination (ILO 1958).

The results are somewhat expected and in line with previous research, but also interesting, especially regarding the influence of culture. Domestic factors, mainly the democratization index and the gender equality index have a very strong positive impact on the introduction of antidiscrimination regulations. Countries with women in power 
and active in public life are more likely to implement antidiscrimination regulations for the community. This is not surprising, as previous research has found this association as well (Johnson 2016; Velasco 2018). Interestingly, the ratification of the ILO's C111 convention did not have any significant effect, a result counterintuitive to the common line of argumentation in previous research that international organizations drive the diffusion of this policy type. On the other hand, the ratification of this policy might as well be "myth and ceremony" to appease world society, while being not implemented on a local level (Meyer and Rowan 1977). In addition, the organizations credited with success for the implementation of policies supporting the LGBTQ+ community are usually topic-specific and very active on a local level, in contrast to the transnational scope of the ILO (Velasco 2018). A country's embeddedness in the globalized world through the trade network also has a positive impact. Trade with many different countries might go along with a certain level of openness. This effect is not to be confused with the classical measures for trade openness, the proportion of trade on GDP, which was not significant in this analysis. The important aspect for this measurement is then the number of ties, rather than the percentage of trade on national GDP. This effect might be spurious, as Western, industrialized, Englishspeaking countries, who tend to trade more than most other countries, have already adopted the policy, as Fig. 9.2 suggests. This supports the suspicion that this policy does not diffuse via the expected pathway-if at all-and relies more on domestic factors. The most interesting result of the analysis is the negative effect of the cultural spheres network. Countries sharing cultural characteristics do not cause contagion, in contrast, it slows the diffusion down. However, this might be the case for only some countries: Fig. 9.2 indicates, in contrast to the analysis results, that language, and therefore one aspect of cultural similarity as measured in the network, seems to be an influence on the adoption of antidiscrimination policies. My suspicion therefore is that culture does matter in the implementation of this policy, however, it might only be a positive influence for some cultural spheres, while hindering diffusion in others. 
Aside from the effect of trade, none of the exposure terms were positive. This leads to the conclusion that this type of policy does not diffuse through networks of shared cultural characteristics or similarity, at least not for all cultural spheres. The negative exposure term of culture can also be explained by adverse effects through shaming (Terman 2019) and a polarization to the Western "homocolonialist" agenda, as Rahman described it (2014). The results are in line with previous studies highlighting the importance of local activism and local problem pressure to implement LGBTQ+ protection policies. It seems that this specific policy does not follow the "usual" social policy diffusion pathways, but depends on local conditions, such as societal values instead of global influence.

\section{Limitations}

As with any other study, this analysis has limitations. The missing data for GDP per capita had to be interpolated. Additionally, the oil crisis in 1973 led to a very sharp increase in GDP per capita for Kuwait, Qatar, Norway, and the United Arab Emirates, resulting in outliers potentially influencing the analysis - even though this data is not a measurement error. Additionally, the gender equality index had to be interpolated as well, as this indicator ends in 2003. Second, the starting point of the logistic hazard model is chosen somewhat arbitrarily, as countries were at 'risk' of implementing these policies far before 1949. The changes to this policy in the last 10 years were drastic and an expansion of the data is planned. The use of discrete-time points is another limitation here; however, the model fit did not significantly change with the use of time as a linear predictor. ${ }^{7}$ Furthermore, the particularities of modelling longitudinal analyses with a changing country sample for the same geographical area have to be kept in mind. It would be beneficial to include IO or NGO networks into this analysis, as they are potentially stronger drivers for this policy than the included networks, as research shows

${ }^{7}$ Model not shown. 
(e.g., Velasco 2020a), but the interaction between the present networks and IO membership is left for future research to discover. In addition, measures for local activism and interest groups could also shed more light on the implementation of these policies. Culture as a predictor of this policy is irrefutable, but there might be conflicting aspects of culture not clearly distinguishable with the cultural spheres network. As mentioned before, certain religious orientations are a counterproductive characteristic (Rahman 2014), but have been combined into the network with other characteristics such as government ideology, resulting in the above effects. In addition, it has to be mentioned that world society models can only provide limited explanations in some cases, as they do not fully account for prolonged adverse effects of exposure. Previous studies could show that controversial issues such as LGBTQ+ rights might not be fully captured through this theoretical framing, as norms in society have to be shared, but the pressure through this model mainly rests on policymakers (Velasco 2020b). Roberts (2019) suggests the use of multiple modernities theory instead to take a closer look at culture-specific attitudes and reactions to international pressure. Despite these limitations, I feel that the model presented here still shows interesting results, as they reveal the strong influence of local conditions over the networks, and the negative effect of cultural similarity, pointing toward different mechanisms of policy diffusion in contrast to other studies in this volume, depending on the specific policy.

\section{Appendix}

See Table (9.2) 
Table 9.2 The introduction of workplace antidiscrimination regulations, $N=$ 126 countries, 1949-2010 non-normalized colonial network

\begin{tabular}{|c|c|c|c|c|}
\hline & \multicolumn{4}{|c|}{$\begin{array}{l}\text { Introduction of workplace } \\
\text { antidiscrimination laws }\end{array}$} \\
\hline & (1) & (2) & (3) & (4) \\
\hline > 1995 & $0.000^{* * *}$ & $0.000^{* * *}$ & $0.000^{* * *}$ & $0.000^{* * *}$ \\
\hline 1995-2003 & $0.000^{* * *}$ & $0.000^{* * *}$ & $0.000^{* * *}$ & $0.000^{* * *}$ \\
\hline 2004-2010 & $0.000^{\star * *}$ & $0.000^{* * *}$ & $0.000^{\star * *}$ & $0.000^{* * *}$ \\
\hline $\begin{array}{l}\text { GDP per capita/10000 } \\
\text { USD }\end{array}$ & 1.170 & 1.183 & 1.260 & 1.226 \\
\hline democratization & $1.699^{\star * \star}$ & $1.678^{* \star \star}$ & $1.870^{\star * \star}$ & $1.898^{\star \star}$ \\
\hline $\begin{array}{l}\text { ratification of ILO } \\
\text { convention C-111 }\end{array}$ & 3.507 & 3.596 & 3.063 & 3.063 \\
\hline gender equality index & $1.139^{* * *}$ & $1.134^{* * *}$ & $1.144^{* * *}$ & $1.143^{* * *}$ \\
\hline degree trade network & $1.025^{*}$ & $1.022^{+}$ & $1.030^{*}$ & $1.027^{+}$ \\
\hline $\begin{array}{l}\text { cultural spheres net.: } \mathrm{w} . \\
\text { exposure (lag } 1 \text { year) }\end{array}$ & $0.011^{*}$ & $0.011^{*}$ & $0.0004^{* *}$ & $0.0003^{* *}$ \\
\hline $\begin{array}{l}\text { colonies net.: w. exposure } \\
\text { non-normalized }\end{array}$ & & 0.233 & 0.166 & 0.199 \\
\hline $\begin{array}{l}\text { trade net.: w. exposure } \\
\text { (lag } 1 \text { year) }\end{array}$ & & & 123.221 & 45.839 \\
\hline $\begin{array}{l}\text { spatial proximity net.: w. } \\
\text { exposure (lag } 1 \text { year) }\end{array}$ & & & & 4.486 \\
\hline Observations & 7448 & 7448 & 7448 & 7448 \\
\hline Log Likelihood & -150.315 & -149.912 & -148.423 & -148.229 \\
\hline Akaike Inf. Crit & 318.631 & 319.824 & 318.846 & 320.459 \\
\hline
\end{tabular}

Note $+p<0.1 ;{ }^{*} p<0.05 ;{ }^{* *} p<0.01 ;{ }^{* *} p<0.001$

\section{References}

Aldridge, Bailey. 2021. "No More 'He' or 'She'. House Approves GenderNeutral Terms in Its Official Language." McClatchy. Accessed February 23, 2021. https://www.mcclatchydc.com/news/politics-government/articl e248264460.html.

Allen, Samantha. 2017. "Millennials Are the Gayest Generation." Daily Beast. Accessed February 23, 2021. https://www.thedailybeast.com/millennials-arethe-gayest-generation.

"Alphabet Mafia." 2020. urbandictionary.com. Accessed February 23, 2021. https://www.urbandictionary.com/define.php?term=AlphabetMafia. 
Ayoub, Phillip M. 2015. "Contested Norms in New-Adopter States: International Determinants of LGBT Rights Legislation." European Journal of International Relations 21 (3): 293-322.

Ayoub, Phillip M, and Douglas Page. 2020. "When Do Opponents of Gay Rights Mobilize? Explaining Political Participation in Times of Backlash against Liberalism.” Political Research Quarterly 73 (3): 696-713.

Barbieri, Katherine, and Omar M. G. Keshk. 2016. Correlates of War Project Trade Data Set Codebook, Version 4.0. Accessed February 23, 2021. http:// correlatesofwar.org.

Becker, Bastian. 2019. "Colonial Dates Dataset” (COLDAT). https://doi.org/ 10.7910/DVN/T9SDEW.

Besche-Truthe, Fabian, Helen Seitzer, and Michael Windzio. 2020. "Cultural Spheres-Creating a Dyadic Dataset of Cultural Proximity." SFB 1342 Technical Paper Series 5. Bremen.

Boli, John, and George M Thomas, eds. 1999. Constructing World Culture: International Nongovernmental Organizations Since 1875. Stanford: Stanford University Press.

Busemeyer, Marius R. 2009. "From Myth to Reality: Globalisation and Public Spending in OECD Countries Revisited: Research Note." European Journal of Political Research 48 (4): 455-482.

Casey, Logan S., Sari L. Reisner, Mary G. Findling, Robert J. Blendon, John M. Benson, Justin M. Sayde, and Carolyn Miller. 2019. "Discrimination in the United States: Experiences of Lesbian, Gay, Bisexual, Transgender, and Queer Americans.” Health Services Research 54: 1454-1466.

Colvin, Roddrick A. 2004. "Agenda Setting, Innovation, and State Gay Rights Policy: An Event History Analysis.” American Review of Politics 25: 241263.

Dilli, Selin, Sarah G. Carmichael, and Auke Rijpma. 2019. "Introducing the Historical Gender Equality Index." Feminist Economics 25 (1): 31-57.

Dobbin, Frank, Beth Simmons, and Geoffrey Garrett. 2007. "The Global Diffusion of Public Policies: Social Construction, Coercion, Competition, or Learning?" Annual Review of Sociology 33 (1): 449-472.

Edsall, Nicholas. 2003. Toward Stonewall: Homosexuality and Society in the Modern Western World. Charlottesville: University of Virginia Press.

Eiser, Lara, Michael Lischka, and Tobias Tkaczick. 2020. Calculating Distances between Capital Cities in ArcGIS using the CShapes Dataset. SFB 1342 Technical Paper Series 1. Bremen.

Encarnación, Omar G. 2014. "Gay Rights: Why Democracy Matters.” Journal of Democracy 25 (3): 90-104. 
Fernández, Juan J., and Mark Lutter. 2013. "Supranational Cultural Norms, Domestic Value Orientations and the Diffusion of Same-Sex Union Rights in Europe, 1988-2009.” International Sociology 28 (1): 102-120.

Head, Keith, and Thierry Mayer. 2014. "Gravity Equations: Toolkit, Cookbook, Workhorse.” In Handbook of International Economics Vol. 4, edited by Gita Gopinath, Elhanan Helpman, and Kenneth Rogoff, 131-195. Amsterdam: Elsevier.

ILO. 1958. Discrimination (Employment and Occupation) Convention C 111. Accessed January 14, 2021. https://www.ilo.org/dyn/normlex/en/f?p= NORMLEXPUB:12100:0::NO::P12100_ILO_CODE:C111.

Inklaar, Robert, Harmen de Jong, Jutta Bolt, and Jan van Zanden. 2018. "Rebasing 'Maddison': New Income Comparisons and the Shape of LongRun Economic Development." GDC Research Memorandum GD-174. Groningen Growth and Development Centre, University of Groningen.

Johnson, Olatunde C. A. 2016. "The Local Turn; Innovation and Diffusion in Civil Rights Law." Law and Contemporary Problems 79. Columbia Public Law Research Paper: 115-144.

"LGBT History." 2021. wikipedia.org. Accessed February 23, 2021. https://en. wikipedia.org/wiki/LGBT_history\#Ancient_history.

Lührmann, Anna, Marcus Tannenberg, and Staffan I. Lindberg. 2018. "Regimes of the World (RoW): Opening New Avenues for the Comparative Study of Political Regimes." Politics and Governance 6 (1): 60-77.

McKelvey, Richard D., and William Zavoina. 1975. "A Statistical Model for the Analysis of Ordinal Level Dependent Variables." The Journal of Mathematical Sociology 4 (1): 103-120.

Mendos, Lucas Ramon, Kellyn Botha, Rafael Carran Lelis, Enrique Lopéz de la Penna, Ilia Savelev, and Daron Tan. 2020. State-Sponsored Homophobia 2020: Global Legislation Overview Update. Geneva.

Meyer, John W., John Boli, George M. Thomas, and Francisco O. Ramirez. 1997. "World Society and the Nation-State." American Journal of Sociology 103 (1): 144-181.

Meyer, John, and Brian Rowan. 1977. "Institutionalized Organizations: Formal Structure as Myth and Ceremony." Journal of Economic Sociology 12 (1): 43-67.

Raeburn, Nicole C. 2004. "Working It out: The Eergence and Diffusion of the Workplace Movement for Lesbian, Gay, and Bisexual Rights." Research in Social Movements, Conflicts and Change 25: 187-230.

Rahman, Momin. 2014. "Queer Rights and the Triangulation of Western Exceptionalism." Journal of Human Rights 13 (3): 274-89. 
Roberts, Louisa. 2019. "Changing Worldwide Attitudes toward Homosexuality: The Influence of Global and Region-Specific Cultures, 1981-2012.” Social Science Research 80: 114-131.

Taylor, Jami K., Daniel C. Lewis, Matthew L. Jacobsmeier, and Brian DiSarro. 2012. "Content and Complexity in Policy Reinvention and Diffusion: Gay and Transgender-Inclusive Laws Against Discrimination." State Politics and Policy Quarterly 12 (1): 75-98.

Terman, Rochelle. 2019. "Rewarding Resistance: Theorizing Defiance to International Shaming." Chicago: University of Chicago. Accessed January 15, 2021. http://rochelleterman.com/wp-content/uploads/2019/06/ Terman_Defiance_06_11_2019.pdf.

The Williams Institute. 2020. "Adult LGBT Population in the United States.”. Accessed February 23, 2021. https://williamsinstitute.law.ucla.edu/publicati ons/adult-lgbt-pop-us/.

UN General Assembly. 1948. "Universal Declaration of Human Rights". Accessed January 15, 2021. https://www.refworld.org/docid/3ae6b3712c. html.

UN General Assembly. 1966. "International Covenant on Economic, Social and Cultural Rights, International Covenant on Civil and Political Rights and Optional Protocol to the International Covenant on Civil and Political Right”. Accessed January 15, 2021. https://www.refworld.org/docid/3b00f4 7924.html.

Valente, Thomas Q. 1995. Network Models of the Diffusion of Innovations. New Jersey: Hampton.

Vega Yon, George, and Thomas W. Valente. 2020. "netdiffuseR: Analysis of Diffusion and Contagion Processes on Networks". R package version 1.22.0. https://doi.org/10.5281/zenodo.1039317.

Velasco, Kristopher. 2018. "Human Rights INGOs, LGBT INGOs, and LGBT Policy Diffusion, 1991-2015.” Social Forces 97 (1): 377-404.

Velasco, Kristopher. 2020a. "A Growing Queer Divide: The Divergence

Between Transnational Advocacy Networks and Foreign Aid in Diffusing LGBT Policies." International Studies Quarterly 64: 120-132.

Velasco, Kristopher. 2020b. "Queering the World Society: Global Norms, Rival Transnational Networks, and the Contested Case of LGBT Rights." Accessed January 15, 2021. https://osf.io/preprints/socarxiv/3rtje/. 
Open Access This chapter is licensed under the terms of the Creative Commons Attribution 4.0 International License (http://creativecommons.org/ licenses/by/4.0/), which permits use, sharing, adaptation, distribution and reproduction in any medium or format, as long as you give appropriate credit to the original author(s) and the source, provide a link to the Creative Commons license and indicate if changes were made.

The images or other third party material in this chapter are included in the chapter's Creative Commons license, unless indicated otherwise in a credit line to the material. If material is not included in the chapter's Creative Commons license and your intended use is not permitted by statutory regulation or exceeds the permitted use, you will need to obtain permission directly from the copyright holder.

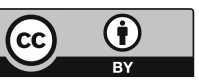

